\title{
Manejo florestal: questões econômico-financeiras e ambientais
}

\author{
IRENE GARRIDO FILHA
}

\section{Introdução}

$\mathrm{D}$ o POTENCial de 60 milhões de metros cúbicos de madeira em toras avaliado para a Amazônia brasileira, apenas cerca de 10\% tem condições de ser aproveitado pela indústria madeireira, porque a floresta Amazônica não apresenta a mesma densidade de madeiras comercializáveis que o sudeste asiático, por ser muito maior a sua biodiversidade - que representa extraordinário leque de utilização em benefício de seus habitantes e do Brasil.

Com a grande demanda de madeiras duras tropicais pelos países desenvolvidos, as florestas da Malásia e da Indonésia estão próximas da exaustão, enquanto que as do Brasil, onde predomina a floresta Amazônica (da mata Atlântica, só restam $10 \%$, ainda permanecerão por muitos anos, mesmo mantido o ritmo de desflorestamento atual, que é, infelizmente, muito grande, ainda.

Além da exploração por empresários do sul e sudeste do país, vêm penetrando na Amazônia, mais fortemente, as chamadas "madeireiras asiáticas", que, no entanto, não são apenas dessa região da Terra, mas, primordialmente, dos Estados Unidos, Europa e Japão, principais mercados consumidores, liderados pelo último. Os empresários do setor vêm entrando na Amazônia, adquirindo imensas extensões de terra, notadamente no estado do Amazonas - a maior e menos explorada unidade federada quanto à atividade madeireira. É preciso relembrar que a entrada de multinacionais madeireiras começou na década de 70 (Garrido Filha, 1980).

O objetivo do estudo da avaliação dos planos de manejo é sugerir caminhos para o desenvolvimento sustentável, que inclui maiores investimentos em pesquisas científicas básicas e aplicadas e o estudo da melhoria dos aspectos econômico, social e ambiental da exploração. Além disso, do ponto de vista econômico, é fundamental que a Amazônia passe a produzir artefatos de madeira para exportação e para o mercado interno. Assim, agrega-se mais valor ao produto na região. Tal evolução econômica poderá representar, igualmente, desenvolvimento social, com melhores condições de vida para a população regional.

Uma exploração com base na sustentabilidade permitirá um melhor aproveitamento do recurso madeireiro, hoje e no futuro, restringindo as áreas de 
extração seletiva das árvores (porque a atividade, tornando-se rentável, não continuará itinerante) e, conseqüentemente, talvez ampliando a utilização da biodiversidade.

\section{Projeto de uso sustentável para a exploração madeireira: o manejo florestal e suas restrições}

Vem se adotando legalmente, para a Amazônia, planos de manejo florestal como política ambiental correta para a exploração madeireira da grande região. O Código Florestal de 1965, no artigo 15, já determinava: "Fica proibida a exploração sob forma empírica das florestas primitivas da bacia amazônica, que só poderão ser utilizadas em observância a planos técnicos de condução e manejo a serem estabelecidos por ato do Poder Público, a ser baixado dentro do prazo de um ano". Na realidade, somente em 1994, pelo decreto $\mathrm{n}^{\circ} 1.282$, se definiu a exploração florestal sob a forma de manejo sustentável, com base nos princípios gerais e fundamentos técnicos, e, em 1995, o Instituto Brasileiro de Meio Ambiente e dos Recursos Renováveis (IBAMA) especificou o manejo florestal sustentável pela portaria $\mathrm{n}^{\circ} 48$.

Em 1999, o IBAMA tinha cadastrados 658 projetos de planos de manejo florestal na Amazônia, abrangendo área de $17.642 \mathrm{~km}^{2}$. Os estados com maior número de projetos eram: Pará, com 252 (38\%), numa área de $9.415 \mathrm{~km}^{2}(53 \%)$, e Mato Grosso, com 187 (28\%), numa área de $2.460 \mathrm{~km}^{2}$ (14\%). São também as unidades federadas que apresentam os maiores desmatamentos e as maiores produções de madeira industrializada.

O projeto de implantação de planos de manejo florestal encontra dois principais obstáculos, difíceis de serem ultrapassados: primeiro, a falta de pesquisas que os indiquem como os mais adequados do ponto de vista da regeneração das essências comercializáveis extraídas; segundo, os seus altos custos de realização, considerando o baixo nível de investimentos de capital da indústria madeireira como um todo, aliado à falta de interesse da maioria dos madeireiros em adotálos, pois consideram a floresta inextinguível.

Comecemos pelo menos complexo: os altos custos do manejo, relativamente aos lucros dos pequenos e médios madeireiros.

Embora variem, com pequenas diferenças, de uma pesquisa para outra, todas no estado do Pará, os dados do Instituto do Homem e Meio Ambiente da Amazônia (IMAZON) fornecem, no essencial, informações preciosas, sobretudo porque não há outros levantamentos sobre atividade madeireira e investimentos de capital, em diferentes tipos de exploração, na Amazônia (Barros e Veríssimo, 1996):

- das várzeas da região do estuário e do baixo e médio Amazonas paraense;

- da terra firme nessa mesma região;

- da terra firme na região de Paragominas e na de Tailândia; e, ainda,

- da exploração do mogno no Pará. 
Nas quatro regiões estudadas, as pesquisas foram desenvolvidas entre 1989 e 1991. Todos os dados do IMAZON, em dólar, foram convertidos em reais de 1997, por gentileza do dr. Antônio Carlos Ferreira, da Fundação Getúlio Vargas, no Rio de Janeiro. A média do dólar, naquele ano, foi R\$ 1,077958.

Nas tabelas apresentadas, a partir dos dados de valor da produção, custo da produção e renda líquida, completados por outros, pode-se formar um quadro da tipologia dos investimentos.

As serrarias, laminadoras e indústrias de compensado podem ser agrupadas, inicialmente, em classes por valor da produção.

$\mathrm{Na}$ categoria de mais baixo valor $(<\mathrm{R} \$ 100 \mathrm{mil})$ estão as pequenas serrarias das várzeas do estuário e do baixo e médio Amazonas paraense. Entre R\$ $100 \mathrm{mil}$ e R 500 mil, se encontram as serrarias de médio porte do estuário e do baixo e médio Amazonas paraense, exceto as que usam balsa para transportar as toras e as serrarias típicas de Tailândia. Entre R \$ 500 mil e R 1 milhão estão as serrarias de Paragominas e as de porte médio do estuário e do baixo e médio Amazonas paraense, que utilizam balsa. Entre R 1 milhão e R $\$ 5$ milhões se encontram as pequenas serrarias especializadas em mogno. Entre R\$ 5 milhões e R\$ 10 milhões se acham as indústrias de compensados e as laminadoras. Na categoria mais elevada (> R\$ 10 milhões), situam-se as grandes serrarias especializadas em mogno.

Explora-se a madeira da floresta Amazônica com pequenos, médios e grandes investimentos de capital. A categoria de mais baixos investimentos abrange os habitantes da várzea, com poucos rendimentos, mas incentivados pelo apoio de intermediários: comerciantes e compradores de toras das serrarias maiores, que fornecem máquinas ou mesmo pequeno capital.

Os custos da produção são extremamente baixos nas pequenas serrarias das várzeas do estuário e do baixo e médio Amazonas paraense; são baixos nas serrarias de médio porte na região do estuário e do baixo e médio Amazonas paraense e na região de Tailândia; custos médios são encontrados nas serrarias de porte médio da região do estuário e do baixo e médio Amazonas paraense, que usam balsa, e na região de Paragominas. Os maiores custos estão nas serrarias especializadas em mogno e nas indústrias de compensado.

Nos custos da produção incluem-se os da matéria-prima e os da mão-deobra como fatores significativos. Portanto, é importante analisá-los. Os dados relativos à matéria-prima foram levantados em todas as áreas, na pesquisa do IMAZON. Representam entre 33\% e 34\% do total dos custos.

O elevado percentual do valor da matéria-prima nos custos da produção demonstra o mau aproveitamento da madeira extraída, que chega a reduzir-se a metade ou até menos, no processo de beneficiamento, porque se aproveita principalmente o fuste para a fabricação de pranchas. Precisa-se aproveitar o máximo da árvore.

$\mathrm{Na}$ análise do consumo médio de toras em relação à produção anual de madeira serrada em metros cúbicos, em todas as regiões estudadas, observa-se o 
grande e generalizado desperdício de madeira. Utiliza-se até mais do que o dobro de metros cúbicos de toras para obter-se o produto final: a madeira serrada ou o compensado. $\mathrm{Na}$ exploração nas várzeas ou em terra firme, é dominante o mau tratamento das toras, na extração e nas serrarias e indústrias de compensados. Mesmo com a madeira mais nobre - o mogno - há perdas significativas. A atividade madeireira, do ponto de vista do uso do grande patrimônio que é a floresta Amazônica, é altamente depredatória.

Os custos da mão-de-obra só foram pesquisados em Paragominas; representam um terço dos custos da produção. Pensa-se em salários, mas os pagos na Amazônia são bem inferiores aos de outras regiões brasileiras produtoras de madeira. A mão-de-obra não é qualificada. Os operários aprendem o ofício na indústria, trabalhando. É comum, nas áreas mais afastadas, empresários não assinarem as carteiras dos trabalhadores.

Preocupação empresarial com a qualificação do operário e o melhor aproveitamento das árvores extraídas - diminuindo, portanto, o excessivo desperdício verificado mesmo nas empresas certificadas - encontramos apenas em um pequeno empresário de Itacoatiara, também designer, João Bird Costa Pereira, que usava normalmente, para fabricação de móveis, madeiras não aproveitadas pela indústria madeireira certificada, a Madeireira Itacoatiara Ltda (MIL). Ele também estava projetando a organização de curso especializado, para que operários melhorassem seu padrão profissional. Como utilizava madeiras da MIL, estava lançando, no mercado nacional, móveis certificados. Fazia previsão para atingir o mercado externo. Posteriormente, soubemos que seus planos ruíram, porém não conhecemos os motivos. No começo de 2001, a CIKEL, no Pará, também tinha os mesmos objetivos. Apesar de tudo, acreditamos que há condições para melhorar a exploração madeireira, no seu conjunto, formando mão-de-obra especializada, usando a madeira de maneira sustentável e vendendo, fora da região, artefatos de madeira.

Quanto aos percentuais da renda líquida, observa-se inferiores a 20\%, na região do estuário e do baixo e médio Amazonas paraense, exceto nas serrarias de porte médio, que utilizam caminhão, pois o uso de combustível eleva muito os custos de produção. Neste caso, a renda líquida é a mais baixa encontrada em todas as pesquisas $-6 \%$. Na classe de $20 \%$ a $30 \%$ encontram-se as serrarias típicas de Paragominas e as pequenas e grandes especializadas em mogno. A renda líquida mais alta (superior a 30\%) é observada em Tailândia e nas pequenas serrarias da região do estuário e do baixo e médio Amazonas paraense, e nas de porte médio dessa região, que usam a balsa. 
Renda líquida das indústrias madeireiras

\begin{tabular}{|c|c|c|}
\hline Tipo de indústria & Renda líquida ( $\mathrm{R} \$$ ) & Lucro $(\%)$ \\
\hline Pequenas serrarias das várzeas ................................ & $2.969,77$ & 18 \\
\hline Serrarias de médio porte do estuário I ................ & $33.038,33$ & 6 \\
\hline Serrarias típicas de Tailândia I ............................... & $40.188,40$ & 18 \\
\hline Serrarias de médio porte do estuário II .............. & $64.683,95$ & 16 \\
\hline Serrarias típicas de Tailândia II ............................... & $151.746,36$ & 40 \\
\hline Serrarias típicas de Paragominas ............................ & $183.246,39$ & 25 \\
\hline Serrarias de médio porte do estuário III ............ & $229.874,54$ & 31 \\
\hline Indústrias de laminados e compensados ............. & $637.033,29$ & 10 \\
\hline 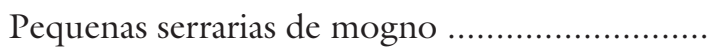 & $947.902,37$ & 28 \\
\hline 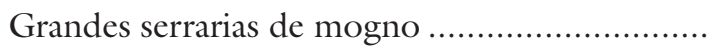 & $3.287 .232,92$ & 29 \\
\hline
\end{tabular}

As serrarias de médio porte do estuário I são as que utilizam o caminhão, tendo, portanto grande despesa de gasolina; as serrarias de médio porte do estuário II usam jangada no transporte das toras; as serrarias de médio porte do estuário III fazem o transporte das toras em balsas.

As serrarias típicas de Tailândia I trabalham apenas sete meses no ano, por falta de capital para armazenarem as toras, enquanto que as serrarias típicas de Tailândia II operam durante $\mathrm{o}$ ano inteiro.

Fonte: Barros, A.C. \& Uhl, C. (1996), p. 125.

Vejamos a questão dos custos dos projetos de manejo. "Uma serraria típica, com uma serra de fita e que atue na exploração florestal, precisa manejar 242 ha/ano para suprir sua necessidade de matéria-prima, a um custo de $\mathrm{R} \$ 46.955,85$ (242 ha multiplicado por R\$194,00/ha). O custo real nos primeiros dois anos de manejo (um ano antes da exploração e um ano após a exploração) seria R \$ 97,00, com investimentos adicionais no décimo e vigésimo anos do ciclo de manejo. Considerando o lucro anual de uma serraria típica como sendo aproximadamente R\$ 232 mil, os custos de manejo consumiriam 20\% dos lucros totais ou $7 \%$ da receita bruta anual total. Ainda que nenhum benefício resulte do manejo, a margem de lucro das serrarias seria diminuída de apenas $32 \%$ para $26 \%$, devido ao investimento em manejo" (Veríssimo, 1996: 68).

Analisando as afirmações acima, verificam-se alguns equívocos. Nos custos de produção, incluem-se os direitos de exploração, que representam 15\% do total (Veríssimo, 1996: 57). É impossível fazer um plano de manejo para no mínimo 20 anos sem que o empresário possua terras suficientes, visto que ele não pode depender da matéria-prima proveniente de terras alheias, nas quais não tem condições de acompanhar a regeneração da floresta. Assim, mesmo considerando baixo o preço da terra na Amazônia, ele incorrerá em despesas muito elevadas nos dois primeiros anos da implantação do plano de manejo. Fora do alcance, portanto, da maioria dos madeireiros. 
Além disso, não se pode considerar como modelo a serraria típica da região de Paragominas, ainda talvez a maior área madeireira da Amazônia. Aliás, estudos feitos pela EMBRAPA no final da década de 1990 (Silva, 1997) mostram que não havia, na microrregião de Paragominas, nenhum plano de manejo de fato [grifo nosso].

\section{A questão ambiental e a necessidade de pesquisas científicas}

O objetivo da produção no sistema capitalista é o lucro e nenhum empresário aplicará capital sem ter certeza de seu retorno, acrescido do lucro. E ele não investirá sem ter a confirmação do seu acerto. Não há pesquisa básica que garanta o bom resultado do manejo florestal, num prazo de 20-30 anos, apesar de existir legislação a respeito desde 1965. A Superintendência do Desenvolvimento da Amazônia (SUDAM) instalou uma estação experimental em Curuá-Una, porém sem continuidade.

"Não conhecemos nada dessas florestas (dos ecossistemas tropicais); conhece-se o bastante para apontar as ações que são degradantes ou não-sustentáveis, mas pouco ainda para propostas que garantam uma real sustentabilidade, concreta e duradoura. [...] Como o manejo da floresta tropical é uma atividade de longo prazo, sendo ciclos de trinta anos muito citados, os impactos do manejo são difíceis de ser avaliados corretamente, sendo normal que uma outra geração de técnicos avalie os impactos do que a antecessora realizou. [...] O pressuposto básico para um possível manejo adequado de uma população é que haja indivíduos jovens em quantidade e qualidade adequadas para repor, em um tempo previsível e econômico, a população de um patamar de uma nova exploração" (Kageyama, 2000) [grifo nosso].

É preocupante o fato de planos de manejo serem adotados pelo IBAMA como política ambiental desejável para a exploração madeireira sustentável. Isso porque não há, ainda, pesquisas desse tipo de uso em nenhuma floresta tropical no mundo, inclusive na Amazônia, menos ainda para os diferentes ecossistemas florestais da grande região.

Niro Higuchi, pesquisador do INPA, em entrevista para este estudo em agosto de 2000 em Manaus, observou que é melhor o uso do manejo florestal do que o abandono da área florestada após a extração da madeira comercializável e a exaustão das essências procuradas. "O manejo florestal procura reduzir os danos à floresta, reduzir os desperdícios de madeira e aumentar a eficiência das operações de extração" (Barros, 1996: 5). Está certo; porém, não se deve adotar o manejo florestal sem, pelo menos, o concomitante (deveria ser anterior, mas isso não é mais possível) desenvolvimento de pesquisas básicas. Entretanto, ao contrário, o manejo tem sido incentivado pelo IBAMA, com o amparo da lei.

Mesmo com as ponderações de grandes pesquisadores acima citados, Barreto e outros, em estudo específico sobre os custos e benefícios dos planos de manejo, expõem as vantagens de aumento do volume médio extraído por hectare (Barreto, 1998). 
São claras as vantagens do manejo: redução de $26,48 \%$ do desperdício na derrubada e no arraste, que resulta no aumento da produtividade.

Nas soluções apontadas para incentivar o manejo, Barreto e outros propõem incorretamente a alteração da legislação, para permitir a exportação de madeira em toras, o que representaria enorme retrocesso (Barreto, 1998). Tal sugestão não é justificável, uma vez que os autores estão pensando apenas em um dos itens básicos do desenvolvimento sustentável: o econômico, a exportação de madeira. Não se cogitou do aspecto ambiental, da conservação da floresta. O retorno à exportação da madeira em tora serviria para agravar os baixos preços da madeira, atribuídos à legislação que impede a exportação de madeira em toras. "No presente, a proibição da exportação de toras provavelmente mantém os preços no mercado interno relativamente baixos. Se a exportação de toras da floresta nativa fosse liberada, os proprietários rurais poderiam vender as toras para o mercado internacional a preços potencialmente mais atrativos" (Barreto, 1998: 37).

É evidente que a venda de madeira em toras, não acrescentando valor ao produto, é um retrocesso. Havíamos avançado ao exigir a industrialização, mesmo primária, que deve ser incentivada qualitativamente, para agregar valor ao produto. A idéia da liberação da venda de madeira em toras diminuiria também os postos de trabalho nas indústrias do setor madeireiro. Não se atenderia, assim, ao aspecto social, nem ao ambiental, porque se incentivaria a exploração da floresta, sem cuidados. O desejável é a progressiva qualificação profissional dos trabalhadores, o que ainda não existe. $\mathrm{O}$ indicado, portanto, é o incentivo da produção de artefatos de madeira, desde a melhoria e ampliação do setor moveleiro até o da produção de pequenas peças de madeira, como faz a Tramontina na região de Belém.

A floresta Amazônica brasileira teve áreas devastadas irracionalmente nas quatro últimas décadas do século XX, especialmente no chamado "arco do desflorestamento", que abrange o leste do Maranhão, sul do Pará, norte de Mato Grosso e Rondônia, além de ser empobrecida pelo corte seletivo, que ainda não pôde ser avaliado pelo INPE.

No mapa Esboço das áreas desflorestadas e das de corte seletivo de espécies da floresta Amazônica na Amazônia legal, procuramos incluir áreas com desflorestamento e com corte seletivo, porque em muitas delas é difícil separar aquelas exclusivamente de corte seletivo. Estas se baseiam nas informações colhidas em pesquisa de campo por nós realizada em agosto de 2000. Exclusivamente de corte seletivo são as regiões de exploração de mogno e outras essências, no sudeste do Pará; as terras da bacia do rio Juruena e as que lhe ficam a oeste, no Mato Grosso; as várzeas dos rios Juruá, Purus e Madeira, no Amazonas. As terras firmes nesses vales do Amazonas, exceto as do Madeira, são exploradas apenas de maneira seletiva, mas em menor escala do que as várzeas. $\mathrm{O}$ empobrecimento da floresta Amazônica, com o corte tão só seletivo, abrange largas porções da grande região, cuja importância ainda não é conhecida. 


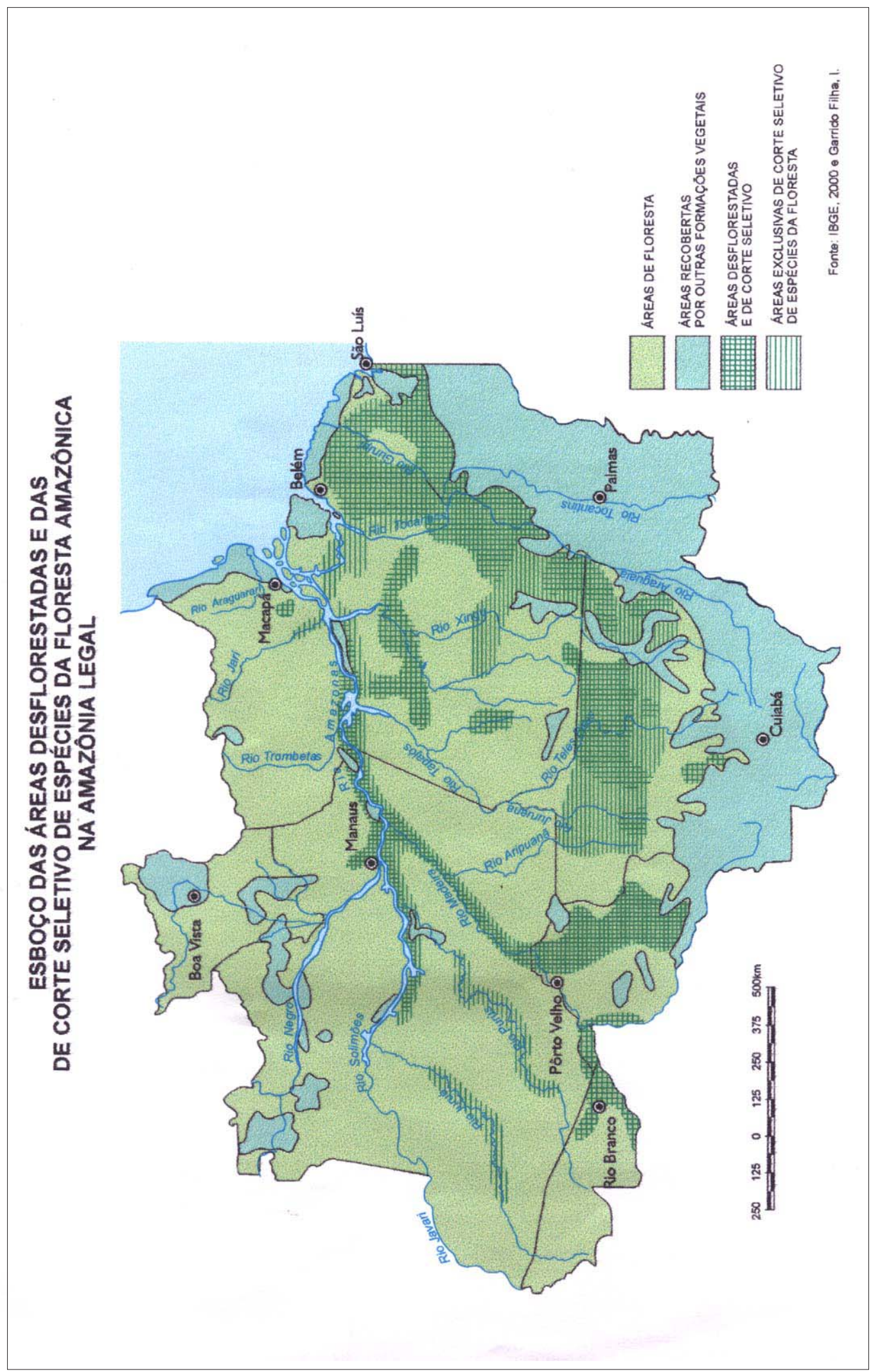


A floresta Amazônica está seriamente ameaçada pela exploração econômica depredatória, especialmente a da madeira - que, embora seletiva na retirada quase exclusiva de espécies de valor comercial, causa graves danos ambientais, porque, geralmente, não se dispensam os cuidados necessários nem na extração nem no beneficiamento, além de a exploração seletiva não contar com experiências anteriores válidas, cronologicamente, para avaliação da regeneração das espécies.

A maioria das ONGs ambientalistas, como é o caso do Greenpeace, atribui a devastação da floresta sobretudo à atividade madeireira, embora este admita a extração seletiva (Greenpeace, 1999). Já os madeireiros afirmam que tal degradação se deve aos agricultores e pecuaristas, responsáveis pelo avanço da fronteira agropastoril, porque praticam a extração a corte raso. Ambos, na realidade, têm responsabilidade pelo mau uso do recurso.

O avanço da fronteira agrícola teve primordial papel no desmatamento da Amazônia, a partir da década de 1960, com os incentivos fiscais à pecuária concedidos pela SUDAM, que devastou áreas consideráveis da floresta, principalmente no Pará, Mato Grosso e Maranhão. Pode-se considerar, ainda, o papel dos pequenos agricultores assentados por meio da política de colonização oficial, especialmente em Rondônia. Nos dois casos, a política da ditadura militar, visando dar acesso à região, abriu grandes eixos rodoviários, como a Transamazônica, a rodovia Santarém-Cuiabá e a Manaus-Porto Velho, bem como asfaltou a BelémBrasília e a Cuiabá-Porto Velho, sem nenhum planejamento nem pesquisa na região. A partir da década de 1970, a exploração madeireira expandiu-se muito, em conseqüência do esgotamento dos recursos florestais do sul e sudeste do Brasil, e também nos demais países tropicais, devido à aplicação de incentivos fiscais à atividade madeireira.

Embora a extração de madeiras não seja feita a corte raso nas áreas florestais exploradas, as empresas do setor estimulam a pecuária, porque compram toras nas áreas florestadas das propriedades pastoris, que precisam de capital para investir na melhoria das pastagens e garantir a continuidade da atividade. Os fazendeiros vendem parte das matas de sua propriedade para, com o dinheiro ganho, recuperar os pastos degradados, porque a criação de gado é, geralmente, extensiva e os solos são pobres para a pecuária. Em terras de pequenos produtores, como na antiga área de colonização de Tailândia (PA), também as empresas madeireiras compravam madeiras dos colonos, assegurando-lhes, com isso, acréscimo à sua baixa renda, resultante da atividade agrícola incipiente - a roça - em terras de solos pobres e inadequados, que não lhes garantia a sobrevivência. A expansão da atividade madeireira, na região do estuário e do baixo e médio Amazonas paraense, se fez com serrarias maiores e compradores financiando a instalação de pequenas serrarias para a população local (Barros e Veríssimo, 1996). Além disso, com o abandono das terras exploradas por corte seletivo, estas são, em geral, completamente desmatadas e ocupadas pela pecuária ou pela agricultura, inclusive da soja, no caso de Paragominas, por exemplo. 
Outro aspecto que deve ser levado em consideração diz respeito à fiscalização do cumprimento da legislação florestal pelos madeireiros, na Amazônia. O estado do Amazonas, por exemplo, com cerca de $1.600 .000 \mathrm{~km}^{2}$, dispunha apenas de 168 agentes fiscais do IBAMA em 2000. Contava, é certo, também com a eventual colaboração do Exército, Marinha, Aeronáutica e da Polícia Federal.

Quanto à fiscalização do IBAMA, são exemplares as reportagens do Jornal do Brasil (8/12/2001, p. 4) e $O$ Globo (30/12/2001, p. 10a). Sabe-se que o Ministério do Meio Ambiente procura todos os anos fazer operações juntamente com outros órgãos, na Amazônia; mas isso não é suficiente. Se não, vejamos: o Jornal do Brasil, em reportagem sobre o mogno, esclarece que a primeira parte da Operação Mogno iniciou-se em junho de 2001 e desmontou 80 acampamentos de madeireiros clandestinos, apreendendo 600 moto-serras e 1,2 mil metros cúbicos de mogno, no Pará. "Em 1996, o governo estabeleceu moratória de dois anos a novos projetos de extração do mogno (a mais valiosa madeira da Amazônia). Ela vem sendo reeditada e valia até junho de 2002. Continuaram legais apenas os projetos anteriores à moratória. Em 1999, 65 deles foram avaliados. Sobreviveram os atuais dezoito" (Garda, 2001: 4).

Desses 18 projetos que tiveram autorização de financiamento, o IBAMA, em 22 de outubro de 2001, suspendeu dezessete que tinham autorização para extrair e vender a madeira. Ela só existe no Pará, Mato Grosso e Acre. O único projeto que continuou autorizado a explorar o mogno foi o da área dos índios xicrins, que está em processo de regularização. Os das áreas de manejo, anteriores a 1996, perderam a autorização. O IBAMA suspendeu a exploração e venda legal da madeira. No dia 5 de dezembro de 2001, com a Instrução Normativa ${ }^{\circ}$ 22 , retirou a autorização dos últimos planos de exploração aprovados por ele, após auditoria sua, da EMBRAPA, da Secretaria de Meio Ambiente do Pará e de ONGs.

A extração só poderá ser feita no momento em que a empresa exploradora obtiver a certificação ambiental, de empresas qualificadas. "É representada por um selo, recebido por empresas que cumpram cota de exploração do governo e permitam a recuperação do mogno" (Garda, 2001: 4).

Ora, já vimos que o plano de manejo reduz os impactos da extração das madeiras, etc., mas não se conhece por experiências científicas como se dará a regeneração de uma espécie, especialmente a do mogno, que leva cerca de cem anos para se tornar árvore adulta. À primeira vista, parece que o IBAMA pretende passar às empresas certificadoras a função de fiscalização, além de melhorar a qualidade da exploração. A certificação também não garante a regeneração das espécies extraídas; apenas reduz os danos da exploração. Segundo o Jornal do Brasil, o dr. José Lelandi Barroso, chefe da fiscalização do IBAMA, declarou que os madeireiros que não usaram o plano de manejo terão de repor a madeira vendida nos anos 1990. As multas resultantes da Operação Mogno alcançaram R\$ 24 milhões. 
A fiscalização da Receita Federal na exportação de madeiras também não é eficiente. É o que demonstra reportagem publicada em $O$ Globo em 30 de dezembro de 2001 (Denardin, 2001: 10a), em que se noticia a exportação de mogno, essência característica das florestas pluviais, pelo porto de Paranaguá, no Paraná. Numa operação conjunta entre IBAMA, Receita Federal e Polícia Federal, no início de dezembro de 2001, foram apreendidos mil metros cúbicos de mogno no valor de R\$ 3,1 milhões. Seriam embarcados para a África, escala para o importante mercado europeu. O mogno estava sendo classificado como cedro, madeira também avermelhada, com valor equivalente a um terço do da outra. A partir de agora, os contêineres com madeira de exportação serão lacrados, após vistoria. A reportagem refere-se à corrupção existente e apontada pela Polícia Federal.

Ao contrário da frente pioneira do café, no sudeste, nos séculos XIX e XX, que destruiu a maior parte da mata Atlântica sem que se tivessem levantado vozes contrárias, na Amazônia, felizmente, com o desenvolvimento das ciências ambientais fundamentando as campanhas de ONGs, especialmente as ambientalistas, há muitos debates em torno da defesa da ocupação regional com sustentabilidade, e graves denúncias.

A avaliação do potencial madeireiro da Grande Região é da ordem de 60 bilhões de metros cúbicos de madeira em tora (Veríssimo e Barros, 1996). Tal potencial desperta o interesse das grandes multinacionais japonesas, européias e norte-americanas, e também de empresas dos países asiáticos com florestas em exaustão, todas englobadas como "empresas asiáticas" nas denúncias de penetração das empresas estrangeiras na Amazônia, comprando terras florestadas e instalando indústrias.

O relatório de 1999 do Greenpeace informa que, pelo menos, 25 companhias européias, americanas e asiáticas têm investimentos na indústria madeireira da Amazônia, sendo que as dez maiores representam quase a metade do valor total das exportações brasileiras de madeira. A exportação, no entanto, não é, ainda, o principal destino da produção de madeira do Brasil. O setor madeireiro nacional, que já esgotou as reservas do sul e sudeste, voltou-se, há algumas décadas, para a Amazônia.

\section{Conclusões}

O potencial da floresta Amazônica, embora vultoso, está sendo ameaçado pelo uso depredatório das árvores de valor comercial. Os investimentos são relativamente baixos. Há falta de capitais. O desperdício da madeira é enorme. Vimos que se aproveita menos de $50 \%$ das toras no processamento, não só nas serrarias como também nas indústrias certificadas. A instalação das serrarias, na imensidão da floresta, passa a seus proprietários a sensação de que se trata de recurso inesgotável. Os madeireiros pensam que podem deslocar-se sempre para novas áreas florestadas, numa exploração itinerante. Mas a floresta, no ritmo atual do processo de destruição, acabará inexoravelmente. A História o ensina. 


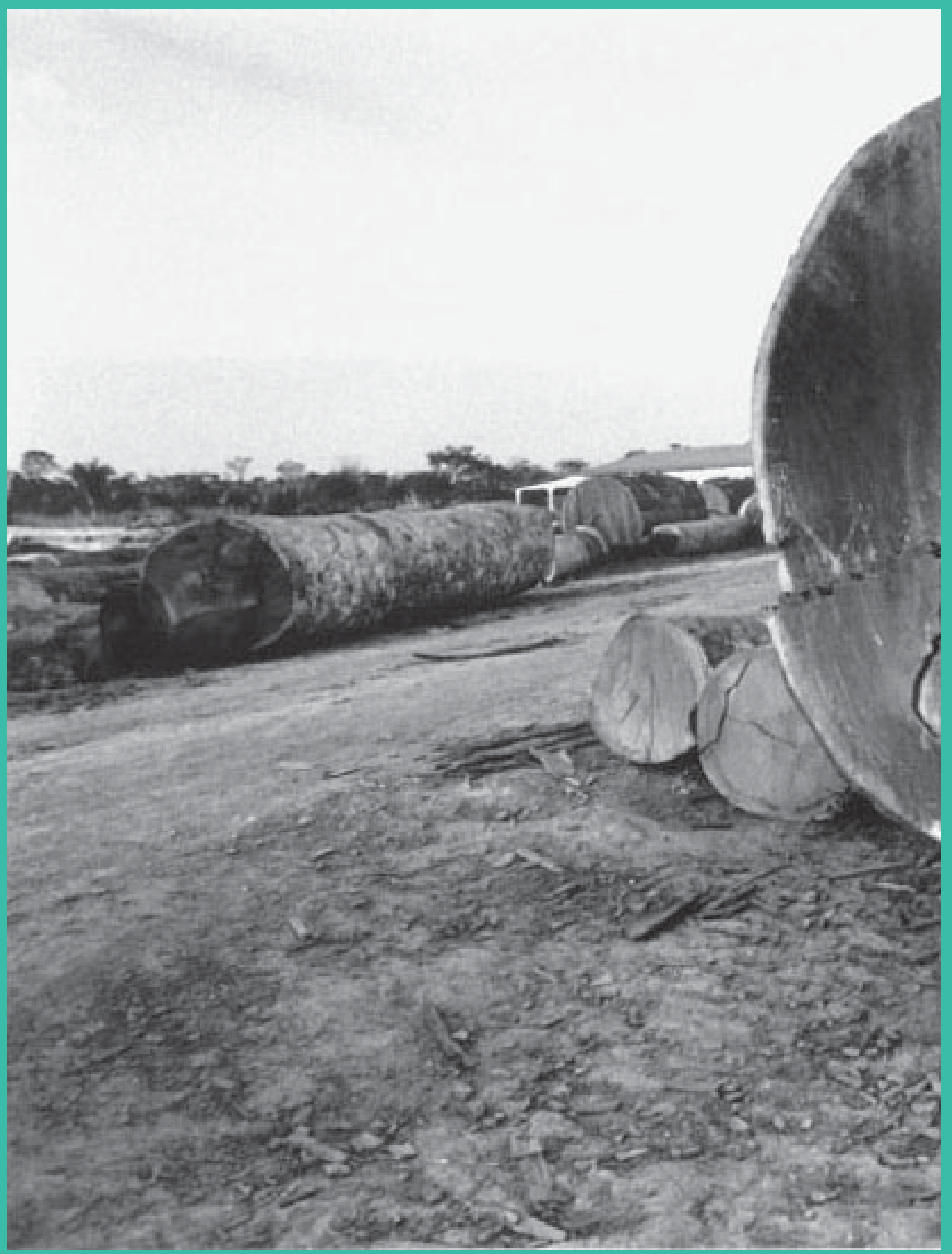




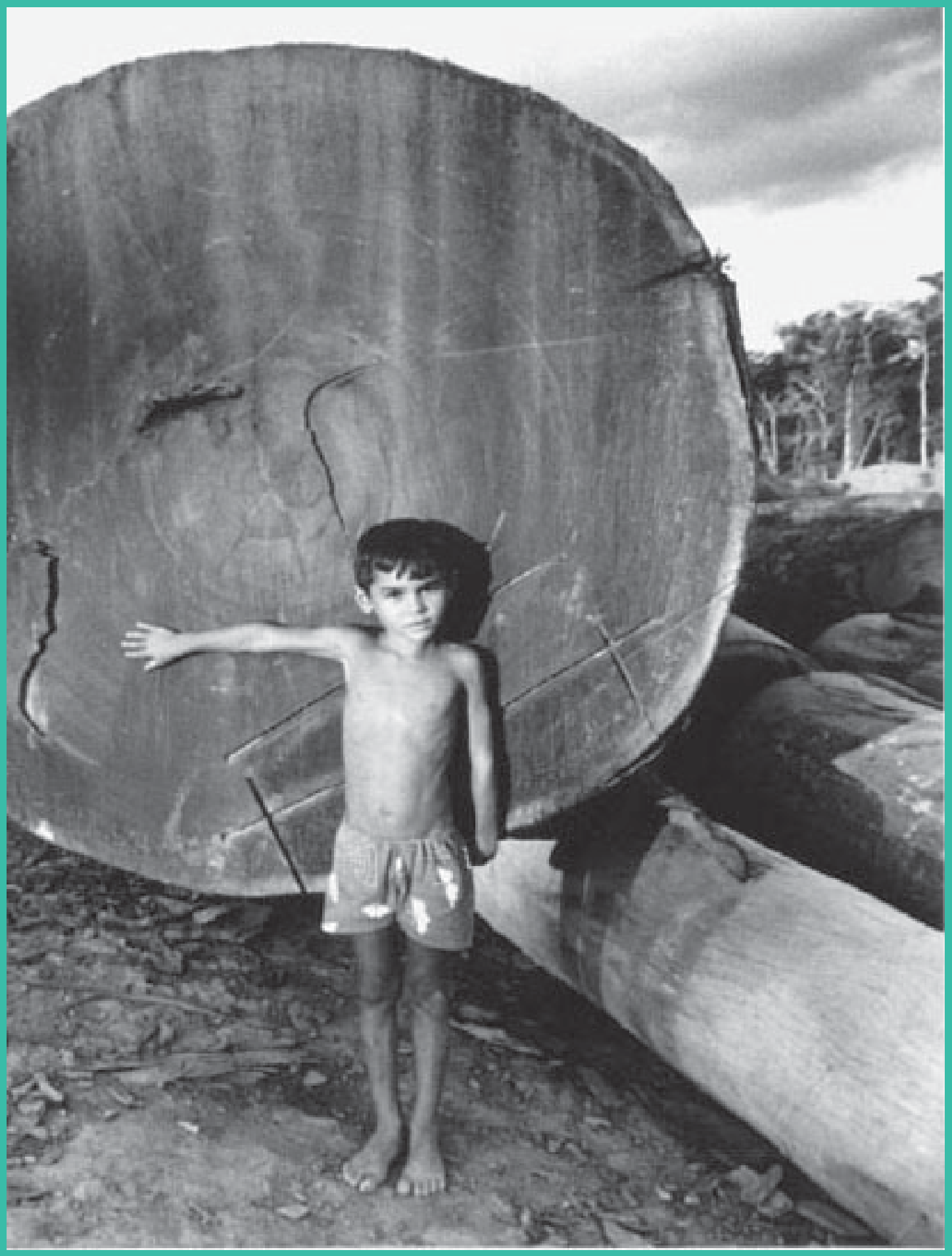

Serraria, Plácido de Castro, Acre, 1987. Foto: Migmel Cbikaoka/Kamava-Kó. 
A recomendação do emprego do manejo florestal data de 1965. Se tivesse sido feito um programa de estudos e acompanhamento de alguns projetos-modelo em áreas diversificadas da Amazônia, teríamos 36 anos de experiência. Pesou também o fato de a regulamentação do Código Florestal só ter ocorrido em 1994. Necessitamos, hoje, de pesquisas em escala "amazônica".

Utiliza-se o inestimável patrimônio de recursos naturais, dos quais a floresta é apenas um deles, sem pesquisas científicas de base e aplicadas, sem nenhum planejamento sério, sem controle e sem fiscalização do seu uso.

Desconhecem-se os direitos básicos das populações nativas: índios, seringueiros e outros coletores e ribeirinhos, verdadeiros donos das terras florestadas e que são delas expulsos pelo latifúndio. Operários das serrarias e das indústrias de compensados não têm formação profissional, são mal remunerados e, mesmo, explorados.

O aproveitamento econômico do recurso florestal (que, diga-se, não se restringe às madeiras; há a biodiversidade, a qual, com o uso que hoje se faz da floresta, desaparecerá) é muito baixo e há desperdício. Há pequenas serrarias financiadas por intermediários que exploram inadequadamente a floresta - como, aliás, também fazem as serrarias de médio porte, as grandes indústrias de compensados e as serrarias de mogno. Multinacionais e capitais brasileiros não se diferenciam, exceto pela remessa de lucros dos primeiros, que ainda se beneficiam com incentivos governamentais de todo tipo.

Esse é o quadro que se observa, hoje, na Amazônia.

Acreditamos que, enquanto no Brasil seus governantes não se conscientizarem, pressionados pela atuação da sociedade organizada, do valor do patrimônio natural de enorme potencial da Amazônia, ela se perderá, pelo uso inadequado tanto dos recursos renováveis, em que se inclui a biodiversidade, quanto dos recursos não-renováveis, como os minérios - sem deslembrar a crescente problemática da água, já escassa em várias partes do mundo.

Urge o estabelecimento de política de larga ampliação dos estudos científicos básicos e aplicados, como os realizados, ainda em pequena monta, pelas instituições científicas da região, aliada a planos de correção da ocupação econômica da Amazônia, numa efetiva política de planejamento regional e com reorganização e urgente ampliação dos setores de fiscalização das atividades econômicas.

Não podemos deixar reduzir-se, sem proveitos econômicos, sociais e ambientais para a região e o Brasil, esse extraordinário patrimônio natural. Temos compromissos com as atuais e as futuras gerações de um país-continente com larga perspectiva de desenvolvimento e influência internacional neste século que ora se inicia. 
Bibliografia

BARRETO, P. et alii. Custos e benefícios do manejo florestal para produção de madeira na Amazônia oriental, Série Amazônia, 10 (Belém: IMAZON, 1998).

BARROS, A. C. e Veríssimo, A. A expansão da atividade madeireira na Amazônia: impactos e perspectivas para o desenvolvimento do setor florestal no Pará (Belém: IMAZON, 1996).

DENARDIN, W. "Proibição não evita exportação ilegal de mogno", O Globo, Rio de Janeiro, 30 dez. 2001, p. 10a.

GARDA, C. "Mogno só pode ser extraído com selo", Jornal do Brasil, Rio de Janeiro 8 dez. 2001 , p. 4.

GARRIDO FILHA, I. O Projeto Jari e os capitais estrangeiros na Amazônia, 2a ed. (Petrópolis: Ed. Vozes, 1980)

GREENPEACE. Face a face com a destruição (São Paulo: Relatório Greenpeace sobre as companhias madeireiras na Amazônia brasileira, 1999).

HIGUCHI, N. O setor florestal da Amazônia brasileira: exploração florestal seletiva e o mercado internacional de madeira dura tropical (Manaus: s.d.)

IBGE. "Vegetação" em Atlas Nacional do Brasil, 3a ed. (Rio de Janeiro: IBGE, 2000), p. 67.

KAGEYAMA, P. “Manejo de florestas tropicais: que paradigma?” em Anais do V Simpósio de Ecossistemas Brasileiros, pp. 72-82, Vitória, 2000.

SILVA, J.N.M. (org.) Diagnóstico dos projetos de manejo florestal no Estado do Pará - fase Paragominas (Belém: EMBRAPA, 1999).

VERÍSSIMO, A. e Barros, A.C.. "A expansão da atividade madeireira na Amazônia” em Barros, A.C. e Veríssimo, A. A expansão da atividade madeireira na Amazônia: impactos e perspectivas para o desenvolvimento do setor florestal no Pará (Belém: IMAZON, 1996) pp. 1-5.

VERÍSSIMO, A. et alii. "Impactos da atividade madeireira e perspectivas para o manejo sustentável da floresta numa velha fronteira da Amazônia: o caso de Paragominas" em Barros, A.C. e Veríssimo, A. A expansão da atividade madeireira na Amazônia: impactos e perspectivas para o desenvolvimento do setor florestal no Pará (Belém: IMAZON, 1996) pp. 45-74.

SUMÁRIO - O MANEjo da floresta Amazônica está previsto no Código Florestal de 1965, mas somente em 1994 foi exigida a exploração sob forma sustentável, o que não é cumprida por falta de controle do IBAMA, por não dispor de pessoal suficiente. Todavia, os principais obstáculos ao manejo florestal são os altos custos de sua implantação, em relação aos lucros da maior parte dos madeireiros, e, principalmente, a falta de pesquisas científicas básicas e aplicadas que garantam a regeneração das espécies extraídas pelo corte seletivo. As políticas públicas não têm priorizado os estudos científicos, que dariam base à exploração dos imensos recursos da Amazônia. 
ABSTRACT - THE MANAGEMENT of the Amazon forest was foreseen in the 1965 Forest Code, but sustainable management was only required in 1994. This, however, was not enforced due to the lack of control by IBAMA (the federal agency in charge of the matter), which lacks personnel. Furthermore, the main obstacles to forest management are the high costs of its implementation, vis-à-vis the profits obtained by most lumber exploiters, and especially the lack of basic and applied research to assure the regeneration of tree species removed by selective cutting. Public policies have not prioritized scientific studies aimed at supporting the proper exploitation of the Amazon's immense resources.

Irene Garrido Filha é pesquisadora e secretária-geral da Campanha Nacional de Defesa e pelo Desenvolvimento da Amazônia (CNDDA), bolsista do CNPq e pesquisadora titular III do IBGE, aposentada. 